\title{
Human Tibial Torsion - Morphometric Assessment and Clinical Relevance
}

\author{
Swati Gandhi ${ }^{1}$, Rajan Kumar Singla ${ }^{2}$, Jagdev Singh Kullar ${ }^{2}$, Gaurav Agnihotri ${ }^{2}$, Vandana Mehta ${ }^{1}$, Rajesh \\ Kumar Suri ${ }^{1}$, Gayatri Rath ${ }^{1}$
}

Background: Tibial torsion is an important anatomical parameter in clinical practice and displays variability among individuals. These variations are extremely significant in view of alignment guides such as those related to rotational landmarks of tibia in total knee arthroplasty. Further, precise knowledge and information pertaining to angle of tibial torsion also helps in correction of traumatic malunion or congenital maltorsion of tibia.

Methods: The present study was carried out to determine the angle of tibial torsion in 100 adult dry tibia bones in the Department of Anatomy, Government Medical College, Amritsar. The study group comprised 50 males and 50 females with equal number of right- and left-sided bones. The measurements were meticulously recorded and the data were subjected to statistical analysis. The results were analyzed and discussed in the light of existing literature.

Results: $\quad$ Ontherightside, it was found tobe $29.84^{\circ} \pm 4.86^{\circ}$ (range $=22.00^{\circ}$ $\left.38.00^{\circ}\right)$ in males and $28.92^{\circ} \pm 5.10^{\circ}$ (range $\left.=15.00^{\circ}-38.00^{\circ}\right)$

\section{At a Glance Commentary}

Scientific background of the subject

The knee joint is one of the most complex and largest joints of the human body. Moreover, it is susceptible to sports injuries commonly.

\section{What this study adds to the field}

Knee arthroplasty has become increasingly popular technique for various knee pathologies both traumatic and congenital. An accurate insight into the angle of tibial torsion is of clinical relevance for knee surgeons to correct tibial malunions and maltorsions. This study hopes to provide baseline data with regards to angle of tibial torsion in Indian population. in females. On the left side, it was found to be $28.00^{\circ} \pm$ $4.94^{\circ}\left(\right.$ range $\left.=20.00^{\circ}-40.00^{\circ}\right)$ in males and $28.12^{\circ} \pm 4.28^{\circ}\left(\right.$ range $\left.=20.00^{\circ}-37.00^{\circ}\right)$ in females .

Conclusion: The present study is an endeavor to provide baseline data with reference to the angle of tibial torsion in the Indian population. The results of the study assume special importance in view of the technical advancements in reconstructive surgical procedures in orthopedic practice.

(Biomed J 2014;37:10-13)

Key words: clinical, reconstructions, tibial, torsion

$\mathrm{T}^{\mathrm{s}}$ ibia torsion, an important morphological feature of human tibia, is defined as any twisting of the tibia on its longitudinal axis which produces a change in alignment of the planes of motion of the proximal and distal articulations. ${ }^{[1]}$ It is one of the structural modifications in human skeleton and begins in utero and progresses throughout childhood and adolescence to skeletal maturity. ${ }^{[2]}$ While majority of the studies address the difference in tibial torsion with right and left limbs, ${ }^{[3]}$ only one study has identified variation in tibial torsion based on gender. ${ }^{[4]}$

The knowledge of tibial torsion is clinically important as pathological degrees of tibial torsion are usually manifested by gait disturbances characterized by out-toeing or intoeing. ${ }^{[3]}$ In children, it is one of the main causes of rotatory malalignment of the lower extremity ${ }^{[2]} \mathrm{A}$ medial torsion of the leg of sufficient degree leads to two important clinical manifestations, i.e., toeing-in and the waddling gait. In such cases, it is important to direct treatment to the leg rather than to the

From the ${ }^{1}$ Department of Anatomy, Vardhman Mahavir Medical College, New Delhi, India; ${ }^{2}$ Department of Anatomy, Government Medical College, Amritsar, India

Received: Oct. 22, 2012; Accepted: Mar. 12, 2013

Correspondence to: Dr. Vandana Mehta, Department of Anatomy, Vardhman Mahavir Medical College and Safdarjang Hospital,

New Delhi - 110 029, India. Tel: 91-9910061399; Fax: 91-25927322; E-mail: drvandanamehta@ gmail.com

DOI: $10.4103 / 2319-4170.117890$ 
foot. ${ }^{[5]}$ Tibial torsion changes from near neutral at birth to $\approx 20^{\circ}$ of lateral tibial torsion in adulthood. Clinical conditions such as congenital talipes equino varus are associated with abnormal degrees of tibial torsion. It has been stated that intoeing during infancy due to persistent relative medial tibial torsion is a common presenting complaint in pediatric orthopedic practice and has been treated by derotation braces. ${ }^{[6]}$

Tibial torsional deformities may either be congenital, developmental, or post-traumatic. The congenital and developmental deformities usually show spontaneous correction, whereas the post-traumatic variety requires osteotomy if the deformity is severe. The indications for treatment are guided by reasonably accurate and reliable quantitation of torsional deformity. ${ }^{[3]}$

It has been seen that there is a large variation of tibial torsion in different populations and within the same population studied by different methods. The present study is an endeavor to provide baseline data with reference to angle of tibial torsion in the Indian population.

The results of the study assume special importance in view of the technical advancements in reconstructive surgical procedures in orthopedic practice. It is also hoped that these findings would be of great value not only in medicolegal and anthropological work but also in clinical diagnosis and management of tibial deformities.

\section{METHODS}

The material for the present study comprised 100 adult tibia bones of known sex and side of Indian origin obtained from the Department of Anatomy, Government Medical College, Amritsar. The study group comprised 50 males and 50 females with equal number of right- and left-sided bones. The pre-requisite consent was obtained from the ethical committee of the institution. The angle of tibial torsion was defined by Eckhoff $e t$ al., as the angle between the posterior axis of the proximal plateau and the transtibial axis of the ankle. ${ }^{[7]}$ The posterior axis of the proximal plateau was defined as the line joining the two most posterior points of the plateau. The transtibial axis of the distal tibia was defined by drawing a line on distal articular surface of tibia connecting the tip of the medial malleolus to the mid-point of lateral border (fibular sulcus). The angle of tibial torsion was measured with the help of a protractor. For measuring the angle, the posterior borders of proximal plateau of both the condyles were rested on the horizontal surface. Then the angle subtended between the horizontal surface and the line defining transtibial axis of distal tibia was measured with the protractor [ $\angle A O D$ in Figure 1]. Three independent observers measured the angles. Measurements were recorded with utmost care and caution to av oid any error. Care was taken to avoid inter-/intra-observer variability.

The data thus obtained were subjected to statistical analysis to calculate mean values and standard deviation on both right- and left-sided bones of two sexes. Student's $t$-test was used for statistical analysis and the $p$ values were calculated. The results were scrutinized and discussed in the light of available literature. Further, the mean values of length of tibia were compared in relation to the mean values of angle of tibial torsion [Tables 1 and 2].

\section{RESULTS}

The mean values of angle of tibial torsion as observed on the two sides in both male and female bones of the present study are depicted in Table 3 . On the right side, it was found to be $29.84^{\circ} \pm 4.86^{\circ}$ (range $=22.00^{\circ}-38.00^{\circ}$ ) in males and $28.92^{\circ} \pm 5.10^{\circ}$ (range $\left.=15.00^{\circ}-38.00^{\circ}\right)$ in females. The corresponding values on the left side were $28.00^{\circ} \pm 4.94^{\circ}\left(\right.$ range $\left.=20.00^{\circ}-40.00^{\circ}\right)$ and $28.12^{\circ} \pm 4.28^{\circ}$ (range $\left.=20.00^{\circ}-37.00^{\circ}\right)$, respectively. Thus, on the right side, the value was greater in males, but on the left side, it was greater in females. However, the difference was statistically

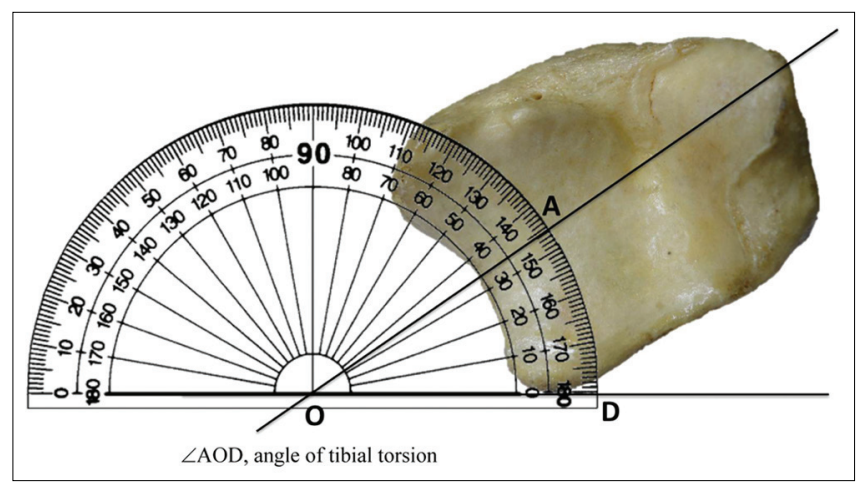

Figure 1: Measurement of angle of tibial torsion.

Table 1: Length of tibia in relation to angle of tibial torsion

\begin{tabular}{lcc}
\hline Parameters & \multicolumn{2}{c}{ Mean \pm SD $(n)$} \\
\cline { 2 - 3 } & Male right & Female right \\
\hline Length $(\mathrm{mm})$ & $387.08 \pm 20.36(25)$ & $356.88 \pm 20.82(25)$ \\
Angle of tibial torsion & $29.84^{\circ} \pm 4.86^{\circ}(25)$ & $28.92^{\circ} \pm 5.10^{\circ}(25)$ \\
\hline
\end{tabular}

Table 2: Length of tibia in relation to angle of tibial torsion

\begin{tabular}{lcc}
\hline Parameters & \multicolumn{2}{c}{ Mean \pm SD $(n)$} \\
\cline { 2 - 3 } & Male left & Female left \\
\hline Length & $382.08 \pm 32.35(25)$ & $353.60 \pm 28.66(25)$ \\
Angle of tibial torsion & $28^{\circ} \pm 4.94^{\circ}(25)$ & $28.12^{\circ} \pm 4.28^{\circ}(25)$ \\
\hline
\end{tabular}

Table 3: Average angle of tibial torsion

\begin{tabular}{lcc}
\hline Sexlside & \multicolumn{2}{c}{ Mean \pm SD $(n)$} \\
\cline { 2 - 3 } & Right & Left \\
\hline Male & $29.84^{\circ} \pm 4.86^{\circ}(25)$ & $28.00^{\circ} \pm 4.94^{\circ}(25)$ \\
Female & $28.92^{\circ} \pm 5.10^{\circ}(25)$ & $28.12^{\circ} \pm 4.28^{\circ}(25)$ \\
\hline
\end{tabular}


insignificant on both the sides $(p=0.516$ on the right side and 0.927 on the left side). On comparison between the two sides, it was found to be greater on the right side in both the sexes. However, both these differences were statistically insignificant ( $p=0.190$ in males and 0.551 in females).

\section{DISCUSSION}

A precise measurement of angle of tibial torsion is important in various orthopedic diagnostic and therapeutic procedures. It has been shown that the angle of tibial torsion varies among different populations. Thus, the data obtained from other populations may not be applicable to the Indian subjects.

The findings of the present study reveal wide variability of tibial torsion between individuals. The reason for this wide variation is ill-understood. However, it may be related to developmental abnormalities. We, as anatomists, submit that the variability in the angle of tibial torsion may possibly be attributed to racial influence.

Tables 4-6 show the comparison of angle of tibial torsion between the two sexes of both sides [Table 4] of both sides

Table 4: Comparison of angle of tibial torsion between males and females on both sides

\begin{tabular}{|c|c|c|c|c|}
\hline \multirow{3}{*}{$\begin{array}{l}\text { Authors } \\
\text { (year) }\end{array}$} & \multicolumn{4}{|c|}{ Mean \pm SD (degrees) $(n)$} \\
\hline & \multicolumn{2}{|c|}{ Right } & \multicolumn{2}{|c|}{ Left } \\
\hline & Male & Female & Male & Female \\
\hline $\begin{array}{l}\text { Ledamany } \\
(1909)^{[3]}\end{array}$ & $25(50)$ & $22(50)$ & $22(50)$ & $18(50)$ \\
\hline $\begin{array}{l}\text { Present } \\
\text { study }\end{array}$ & $\begin{array}{c}29.84 \pm 4.86 \\
(25)\end{array}$ & $\begin{array}{c}28.92 \pm 5.10 \\
(25)\end{array}$ & $\begin{array}{c}28.00 \pm 4.94 \\
(25)\end{array}$ & $\begin{array}{c}28.12 \pm 4.28 \\
(25)\end{array}$ \\
\hline
\end{tabular}

Table 5: Comparison of angle of tibial torsion on the right and left sides irrespective of sex

\begin{tabular}{lcc}
\hline Authors (year) & \multicolumn{2}{c}{ Mean \pm SD (degrees) $(n)$} \\
\cline { 2 - 3 } & Right & Left \\
\hline Hutter and Scott $(1949)^{[1]}$ & $22.1(20)$ & $19.8(20)$ \\
Malekafzali and Wood $(1979)^{[8]}$ & $14.5(50)$ & $14(50)$ \\
Larson et al. $(1983)^{[9]}$ & $23.5(45)$ & $23.1(55)$ \\
Clementz $(1989)^{[10]}$ & $30.7 \pm 7.8(-)$ & $28.6 \pm 7.6(-)$ \\
Eckhoff et al. $(1994)^{[7]}$ & $38 \pm 11(224)$ & $33 \pm 9(224)$ \\
& $40 \pm 9(224)$ & $32 \pm 10(224)$ \\
Present study & $29.38 \pm 4.95(50)$ & $28.06 \pm 4.58(50)$ \\
\hline
\end{tabular}

Table 6: Comparison of angle of tibial torsion between males and females irrespective of sides

\begin{tabular}{lcc}
\hline Authors (year) & \multicolumn{2}{c}{ Mean \pm SD (degrees) $(n)$} \\
\cline { 2 - 3 } & Male & Female \\
\hline Hutchins et al. $(1986)^{[11]}$ & $17.4 \pm 2.5(15)$ & $13.9 \pm 2.4(14)$ \\
Yoshioka et al. $(1989)^{[4]}$ & 21 & 27 \\
Present study & $28.92 \pm 4.94(50)$ & $28.52 \pm 4.68(50)$ \\
\hline
\end{tabular}

irresptive of sex [Table 5] and of the two sexes irrespective of sides [Table 6], and compared the findings of the current study with some of the earlier workers. It is evident from the tables that there is a large variation of tibial torsion within the populations studied by different methods. This also confirms the wide variability of tibial torsion between individuals. Torsional variation between right and left tibiae has been previously reported with right tibial torsion consistently greater than the left,,$^{[1,3,7]}$ which is in consonance with the present study. Further, torsional variation between males and females has been documented only once with female predominance ${ }^{[4]}$ which is contradictory to the findings of the present study. Clinically, these variations may be highly significant as it will make the application of alignment guides, such as those keyed to rotational landmarks of the tibia in total knee arthroplasty. The clinical utility of these variations is immense as it provides vital information with regards to the alignment guides prior to knee arthroplasty. Further, the correction of traumatic malunion or congenital maltorsion of the tibia may not be individually accomplished by simply recreating the average torsion for any population studied. ${ }^{[7]}$

The uniqueness of the present investigation lies in the fact that our study was conducted on actual bones. It is pertinent to mention that most of the earlier studies were carried out in patients by using computed tomography (CT) scans and conventional radiographs. The knowledge of tibial torison is clinically important as pathological degrees of tibial torsion are usually manifested by gait disturbances characterized by out-toeing or intoeing. ${ }^{[3]}$

Tibial torsion is the main factor for rotatory malalignment of the lower extremity in childhood. ${ }^{[5]}$ Postures such as postnatal sitting, sleeping, and faulty play habits have been implicated as mechanisms that cause torsional abnormalities. This knowledge is important to the orthopedic surgeons for imparting such information as a prophylactic step. ${ }^{[6]}$ Precise knowledge pertaining to tibial torsion and torsional abnormalities is of immense help in elucidating the pathogenesis of knee osteoarthritis and to facilitate better treatment strategies. Thus, good anatomical insight into human tibial torsion and torsional abnormalities is extremely relevant in orthopedic practice. The present paper is a humble attempt to provide morphometric assessment of human tibial torsion in Indian subjects.

\section{Conclusion}

The present study reveals wide variability of human tibial torsion. The values of angle of tibial torsion were compared between the two sexes and were found to be more in males on the right side and slightly more in females on the left side. However, the difference was statistically insignificant. On the other hand, when compared between the two sides, the value was more on the right side in both the sexes but the difference was statistically insignificant. Clinically, 
these observations are highly significant in view of their application in alignment guides in total knee arthroplasty. The results of the correct study assume special importance in view of the technical advancements in reconstructive surgical procedures in orthopedic practice. The study is also relevant for anthropologists and medicolegal experts. Thus, precise knowledge pertaining to tibial torsion and torsional abnormalities is of immense help in elucidating the pathogenesis of knee osteoarthritis and to facilitate better treatment strategies.

\section{REFERENCES}

1. Hutter CG, Scott W. Tibial Torsion. J Bone Joint Surg 1949;31A: 511-8.

2. Staheli LT, Engel GM. The natural history of torsion and other factors influencing gait in childhood. Clin Orthop 1972;86:183-6.

3. Ledamany. La torsion due tibia, normale pathologique experimentale. J Anat Physiol 1909;45:598-615.
4. Yashioka Y, Siu DW, Scudamore RA, Cooke TD. Tibial anatomy and functional axes. J Orthop Res 1989;7:132-7.

5. Nachlas IW. Medial torsion of the leg. Arch Surg 1934;28:909-19.

6. Knight RA. Developmental deformities of the lower extremities. J Bone Joint Surg 1954;36A: 521-7.

7. Eckhoff DG, Kramer RC, Watkins JJ, Burke BJ, Alongi CA, Stamm ER, et al. Variation in Tibial Torsion. Clin Anat 1994;7:76-9.

8. Malekafzali S, Wood MB. Tibial torsion-A simple clinical apparatus for its measurement and its application to a normal adult population. Clin Orthop and Relat Res 1979;145:154-7.

9. Larsson K, Bergstrom B, Van Der Linden W. A new method for measurement of tibiofibular torsion. Acta Universitatis Upsaliensis 469, Faculty of Medicine Uppsala, Sweden, 1983.

10. Clementz BG. Assessment of tibial torsion and rotational deformity with a new fluoroscopic technique. Clin Orthop Relat Res 1989;245:199-208.

11. Hutchins PM, Rambicki D, Comacchio L, Paterson DC. Tibiofibular torsion in normal and treated clubfoot populations. J Paed Orthop 1986;6:452-5. 